\title{
Characterization of residual stresses in IN 718 turbine discs by neutron diffraction and finite element modelling
}

\author{
Peter Staron $^{1, a}$, Ulrike Cihak ${ }^{2, b}$, Helmut Clemens ${ }^{3, c}$, Martin Stockinger ${ }^{4, d}$ \\ and Andreas Schreyer ${ }^{1, \mathrm{e}}$ \\ ${ }^{1}$ Institute of Materials Research, GKSS Research Centre, Geesthacht, Germany \\ ${ }^{2}$ AIT Austrian Institute of Technology $\mathrm{GmbH}$, Seibersdorf, Austria \\ ${ }^{3}$ Department of Physical Metallurgy and Materials Testing, University of Leoben, Austria \\ ${ }^{4}$ Bohler Forging, Kapfenberg, Austria

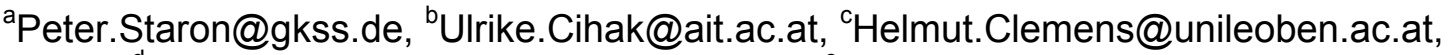 \\ dMartin.Stockinger@bohler-forging.com, ${ }^{\mathrm{e}}$ Andreas.Schreyer@gkss.de
}

Keywords: Nickel-based superalloys; residual stress; neutron diffraction; finite element modelling.

\begin{abstract}
The results of our investigations on residual stresses in commercially produced forged IN 718 compressor discs are reviewed. The residual stresses in the discs with a diameter of $320 \mathrm{~mm}$ and a thickness of up to $25 \mathrm{~mm}$ were studied using neutron diffraction to verify the predictions of a finite element simulation, which was used to model forging and cooling of the discs. In addition to the disc, a thin plate of the same material was also studied for testing the influence of specimen geometry on the model predictions. While the model results for the disc were not strongly influenced by the heat transfer coefficient, the stress distributions in the thin plate could only be predicted satisfactorily by using a temperature-dependent heat transfer coefficient that was derived from temperature measurements during quenching. Eventually, this led to an improvement of the FE simulation used for optimizing the production process.
\end{abstract}

\section{Introduction}

The results of our investigations on residual stresses (RS) in commercially produced forged compressor discs are reviewed [1-6]. The unique combination of high-temperature strength and high fatigue strength makes nickel-based superalloys suitable for turbine components [7, 8]. For further improvement of the high-temperature strength, a special thermo-mechanical processing route has been developed for the Inconel alloy 718 (IN 718) for use in turbine discs of aero engines. Contrary to the conventional heat treatment, where forging is followed by slow air cooling [9], the 'direct age process' requires water quenching directly after forging (Fig. 1) [10,11]. A large number of dislocations are frozen during quenching, acting as potential nucleation sites for the strengthening precipitates that are formed in the subsequent annealing treatment. These precipitates are fine semicoherent $\gamma^{\prime \prime}-\mathrm{Ni}_{3}(\mathrm{Nb}, \mathrm{Ti})$ and coherent $\gamma^{\prime}-\mathrm{Ni}_{3}(\mathrm{Al}, \mathrm{Ti})$ particles.

However, water quenching leads to much higher RS than standard air cooling. Therefore, problems due to distortion arise during the machining of a disc to its final shape when the RS were not completely relieved during the final heat treatment. In the worst case the final geometry of the component cannot be machined out of the forging. Thus, the knowledge about RS in the disc is especially important with respect to distortion caused by material removal during machining. If the RS state within the disc is known prior to turning, the process can be adjusted in order to reduce distortion considerably.

A finite element (FE) model that was used for the simulation of the forging process was also used for the simulation of the water quenching step. The RS predictions of the FE simulation were checked against experimentally determined RS values in a disc that was taken out of the commercial production after forging and water quenching. Due to the relatively large dimensions of the part $(\varnothing$ 
$320 \mathrm{~mm}$, thickness up to $25 \mathrm{~mm}$ ), neutron diffraction (ND) is the only experimental technique to study bulk residual stresses within the disc.

A thin plate ( $6 \mathrm{~mm}$ in thickness) of the same material was also examined. Much less beam time was required for strain measurements in the thin plate due to less absorption. The thin plate allowed testing the influence of geometry on RS modeling.

The heat transfer rate $h(T)$ is a crucial input parameter for the simulation. While the simulation produced a good residual stress prediction for the disc using a constant $h$, the results were poor for the thin plate. Therefore, a temperature-dependent heat transfer coefficient has been estimated from temperature measurements in a disc during water quenching. The use of a temperature dependent $h(T)$ for the thin plate leads to a significant improvement of the simulation.

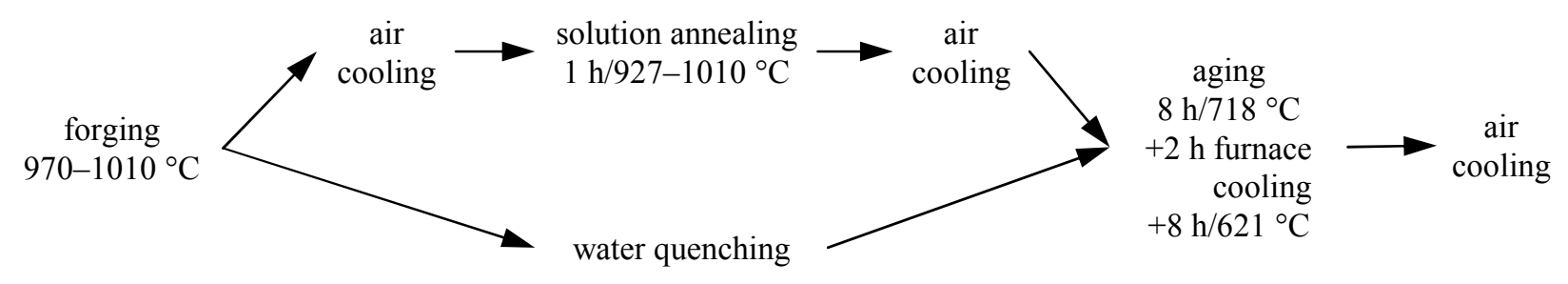

Fig. 1: Overview of conventional and 'direct age' processing routes.

\section{Experiments}

Material. The nickel-based superalloy IN 718 is an alloy developed and optimized for hightemperature applications like turbines. The chemical composition of IN 718 is $52.5 \mathrm{Ni}-19 \mathrm{Cr}-$ 18.5 Fe-3 Mo-0.9 Ti-0.5 Al (wt\%) plus $0.5 \mathrm{wt} \%$ impurities of $\mathrm{Co}, \mathrm{C}, \mathrm{Mn}, \mathrm{Si}, \mathrm{P}, \mathrm{B}$, and $\mathrm{Cu}$. Its strength is achieved by partially coherent $\gamma^{\prime \prime}-\mathrm{Ni}_{3}(\mathrm{Nb}, \mathrm{Ti})$ precipitates as well as coherent $\gamma^{\prime}$ $\mathrm{Ni}_{3}(\mathrm{Al}, \mathrm{Ti})$ precipitates in the face-centered cubic (fcc) matrix. The corresponding elements are predominantly in solution at the forging temperature, precipitates are formed during the heat treatment at $718^{\circ} \mathrm{C}$ [12]. The main strengthening phase is $\gamma^{\prime \prime}$, which can also be present in its thermodynamically stable form, referred to as $\delta$ phase, having the same nominal composition as $\gamma^{\prime \prime}$. Unlike $\gamma^{\prime \prime}$ particles, the $\delta$ phase is not completely dissolved at the forging temperature. However, a quantitative phase analysis performed on SEM images of the as-quenched condition revealed only a small volume fraction of the $\delta$ phase between $3 \%$ and $4 \%$. Therefore, the material can be considered as a single phase and thus, strains determined from the matrix reflections are regarded as representative for the whole sample.

The studied discs had a diameter of $320 \mathrm{~mm}$ and a thickness varying from 15 to $25 \mathrm{~mm}$. They were taken from the standard production at Böhler Schmiedetechnik GmbH \& Co KG, Austria, after a two-step closed-die forging process on a screw press followed by water quenching. The large deformation together with forging below the $\delta$-phase solvus temperature leads to a homogeneous microstructure with a mean grain size of $5 \mu \mathrm{m}$ [10]. In addition, a thin plate with the size $6 \times 50 \times 100 \mathrm{~mm}^{3}$ was cut from a disc. It was subjected to an additional heat treatment at the forging temperature and subsequently quenched in water. Both geometries are shown in Fig. 2.

Temperature measurements. The temperature was recorded during water quenching for the plate as well as for the disc. Coated K-type thermocouples (NiCr-Ni) with a diameter of $1.5 \mathrm{~mm}$ were used to ensure a reaction time of $<1 \mathrm{~s}$. The thermocouples were mechanically fixed in blind holes with the tip close to the opposite surface of the part [4]. The distance between the tip of the thermocouple and the surface was $1 \mathrm{~mm}$ in the plate and $3 \mathrm{~mm}$ in the disc. As a consequence, the recorded temperature is not identical with the surface temperature. Therefore, the influence of heat conduction from the surface to the thermocouple has to be taken into account. Disc and plate were heated up to the forging temperature in a laboratory furnace and subsequently quenched in $20{ }^{\circ} \mathrm{C}$ cold water. In order to minimize the amount of bubbles formed due to the Leidenfrost effect, the discs were submerged in an upright position [3]. 
Neutron diffraction. Strain measurements [13] were performed with the neutron diffractometer ARES at the GKSS Research Centre in Geesthacht, Germany, using a constant wavelength of $\lambda=$ $0.164 \mathrm{~nm}$ [14]. The (311) reflection was used for the measurement because it is recommended for the evaluation of macro-stresses in materials with fcc crystal lattices. The shifts $\Delta(2 \theta)$ of the Bragg peaks were determined using an area detector with an active area of $300 \times 300 \mathrm{~mm}^{2}$. The used coordinate systems and the locations of the scan lines are indicated in Fig. 2. A matchstick-like gauge volume with a cross section of $2 \times 2 \mathrm{~mm}^{2}$ was chosen in order to increase intensity; its length was $30 \mathrm{~mm}$ for measurements of axial and radial strains and $10-15 \mathrm{~mm} \mathrm{~mm}$ for tangential strains. It is thus assumed that the stresses are constant in the hoop direction over the length of the gauge volume [15].

For the discs, the value for the unstrained lattice parameter $d_{0}$ was determined by measuring small cubes (with 4-5 mm edge length) using cubic gauge volumes with 2-3 mm edge length. The cubes were cut out of the discs by electro-discharge machining. Due to the small size of the cubes they were considered to be free of macro-stresses [16]. The diffraction elastic constants (DEC) $E_{\mathrm{hkl}}$ $=195 \mathrm{GPa}$ and $v_{\mathrm{hkl}}=0.31$ for the (311) reflection were used for evaluating RS [6].

For the plate, the stress differences $\sigma_{\mathrm{x}}-\sigma_{\mathrm{z}}$ and $\sigma_{\mathrm{y}}-\sigma_{\mathrm{z}}$ were analyzed for which $d_{0}$ is not required and cutting of a reference sample can be avoided. A cubic gauge volume with an edge length of $3 \mathrm{~mm}$ was used.
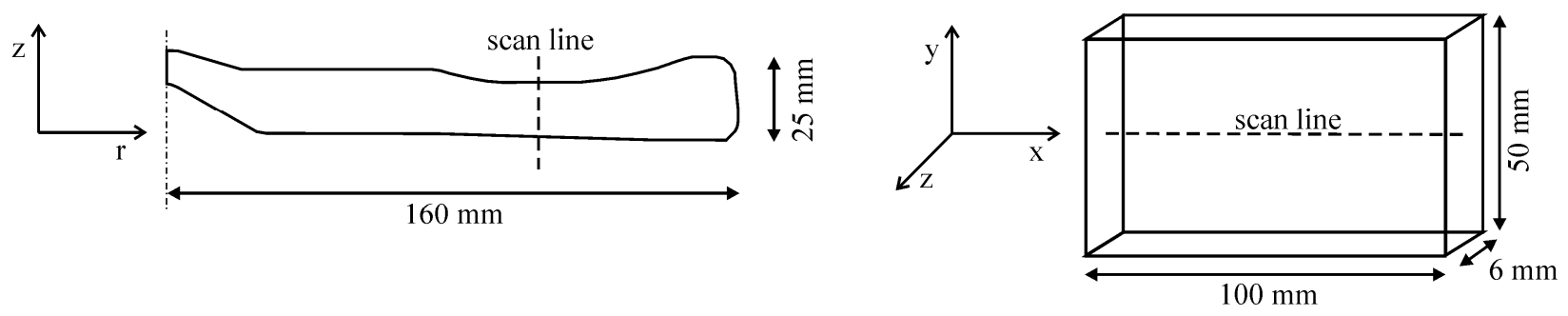

Fig. 2: Geometry of disc (cross section) and plate samples with position of the scan lines.

\section{Finite element modeling}

For the optimization of the forging process of the investigated turbine discs the FE code DEFORM2D ${ }^{\mathrm{TM}}$ was used, which is a special code for hot massive deformation. It was also used for modeling the water-quenching step and for predicting RS. An axi-symmetric stress state was assumed due to the symmetry of the disc and consequently a two-dimensional axi-symmetric model was established. The whole surface of the disc is represented by the contour nodes of the cross section, where the boundary conditions for water-quenching were applied. The FE mesh consisted of 10000 almost rectangular elements.

The material input data, e.g. thermal conductivity, thermal expansion, and heat capacity, were taken from literature [e.g. 17, 18]. The temperature and strain rate dependent flow stress behavior was determined experimentally as the required data were not available in literature for the investigated material. Data for small strain rates are needed for the elasto-plastic regime to describe the cooling step, while large strain rates are involved during forging (plastic regime). Young's modulus and Poisson's ratio were determined dynamically (ultrasonic pulse-echo overlap measurements [19]).

The heat transfer coefficient $h(T)$ cannot be measured directly; therefore, it was deduced from the temperature measurements during water quenching (Fig. 3). The result is the temperature-dependent heat transfer coefficient $h(T)$ shown in Fig. 4; the details can be found in [3]. 


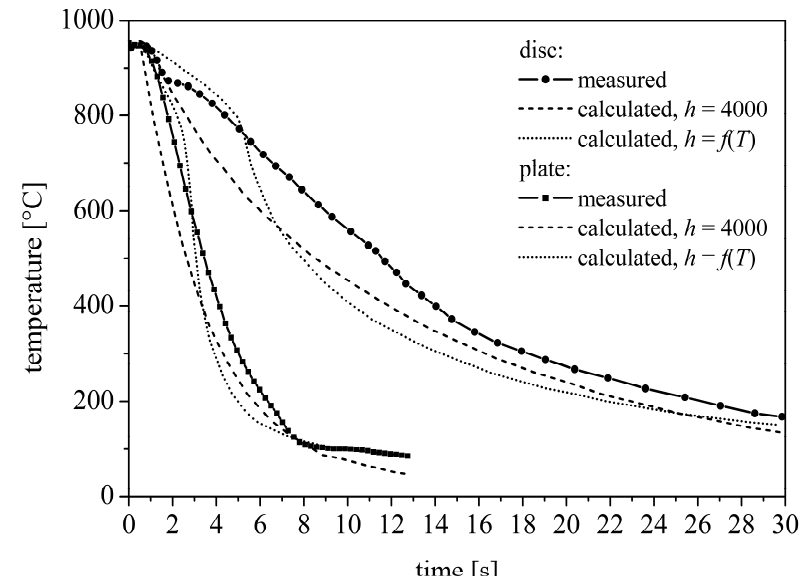

Fig. 3: Comparison of measured temperatures with model predictions for disc and plate. Two different heat transfer coefficients $h$ were used [4]. (The unit of $h$ is $\mathrm{Wm}^{-2} \mathrm{~K}^{-1}$.)

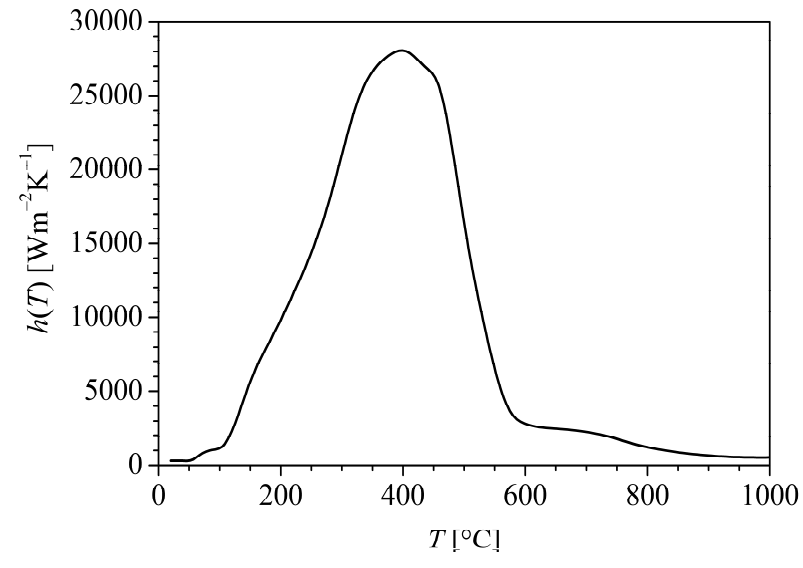

Fig. 4: Estimation of the heat transfer coefficient as a function of temperature as derived from the temperature measurements during quenching [6].

\section{Results and discussion}

$\mathrm{RS}$ in the disc after water-quenching predicted by the FE model in radial and tangential directions are very similar, except at the outer rim of the disc, and through-thickness (axial) stresses are close to zero (Fig. 5). The predictions of the FE model fit well to the measured stresses (Fig. 6). Repeated measurements along three different radii $120^{\circ}$ apart from each other showed a rotational symmetry of the stress state. Originally, the model was used with a constant heat transfer coefficient $h=4000 \mathrm{Wm}^{-2} \mathrm{~K}^{-1}$ [2], which is based on data for water as reported in literature [20].

However, satisfying results could not be achieved for thin plate using a constant $h$. The agreement was very poor between measured and calculated stresses for $h=4000 \mathrm{Wm}^{-2} \mathrm{~K}^{-1}$ (Fig. 7). The simulation gives flat stress distributions while measured stresses vary significantly over the length of the plate. Also a variation of the value of $h$ did not improve the predictions. A systematic variation of various input parameters of the simulation revealed that a more detailed knowledge of the heat transfer coefficient $h$ as a function of temperature is required for improving the model in case of the thin plate [21]. The smaller thickness, leading to a faster cooling of the plate, seems to be responsible for a stronger influence of the exact function of $h(T)$ on the predicted stress distribution. With $h(T)$ estimated from the temperature measurements, the FE results could be significantly



Fig. 5: Stress distributions over the cross section of a disc as predicted by the FE model. The dashed line marks the position of the scan line for neutron diffraction [6].

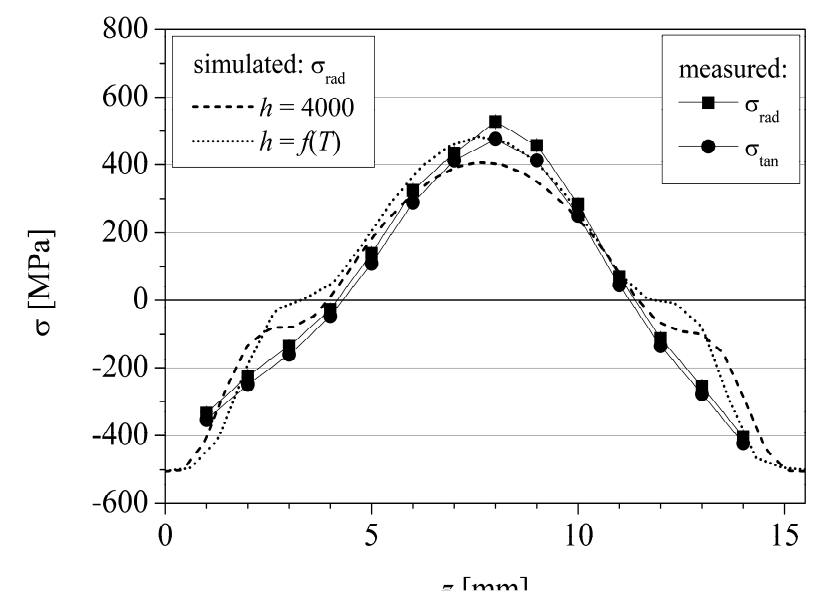

Fig. 6: Comparison of measured (symbols) and simulated stresses through the thickness of the disc. The model prediction for radial stresses is shown for different heat transfer coefficients $h$ (dashed and dotted lines; the unit of $h$ is $\mathrm{Wm}^{-2} \mathrm{~K}^{-1}$ ) [6]. 

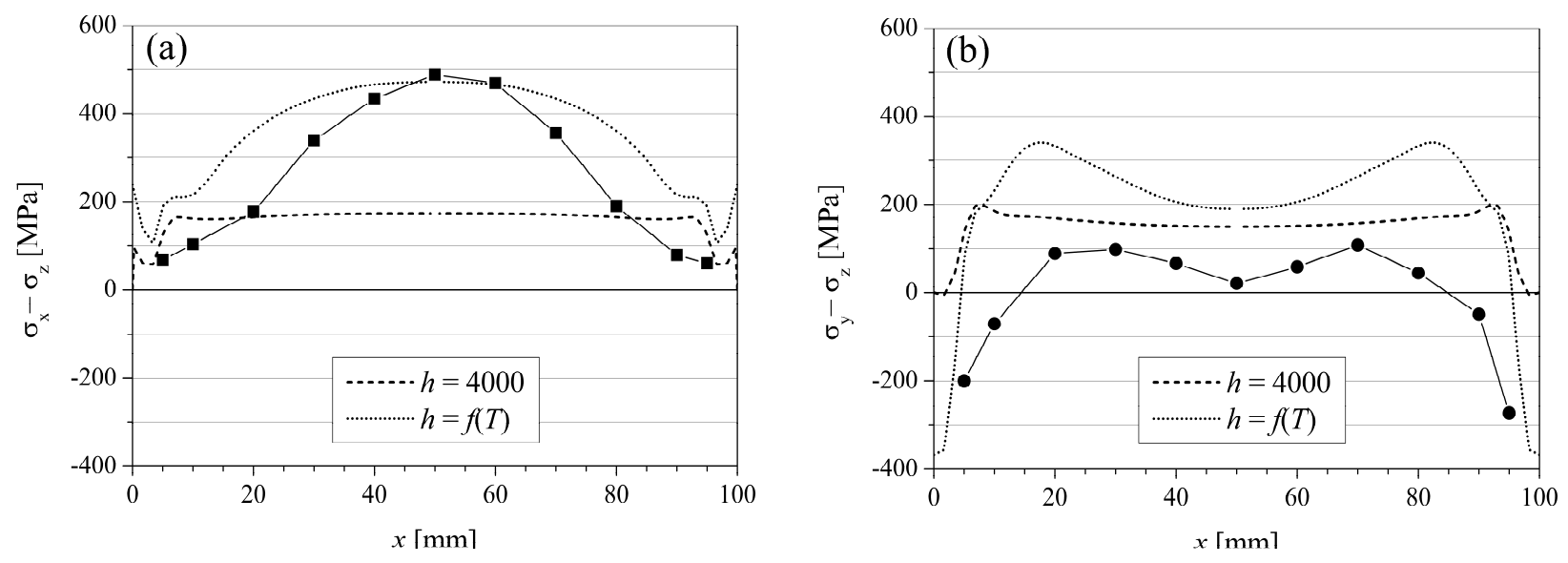

Fig. 7: Comparison of measured (symbols) and simulated stresses for the thin plate. a) $\sigma_{\mathrm{x}}-\sigma_{\mathrm{z}} ; \mathrm{b}$ ) $\sigma_{\mathrm{y}}-\sigma_{\mathrm{z}}$. (The unit of $h$ is $\mathrm{Wm}^{-2} \mathrm{~K}^{-1}$ ) [6].

improved (Fig. 7). Nevertheless, the details need still further improvement. It must be noted that discrepancies between simulation and measurement can partly be due to a resolution effect: While the measurement gauge volume in the plate had a size of approximately $3 \times 3 \times 3 \mathrm{~mm}^{3}$, the calculated data were not yet be integrated over a corresponding volume. However, this influence is considered to be relatively small and therefore will not lead to major changes in the presented results.

The influence of $h(T)$ on the RS predictions for the disc seems to be rather small (Fig. 6). This means that good RS predictions are already obtained with constant $h$. However, the influence of the specimen geometry on the RS predictions still has to be investigated in more detail.

\section{Summary}

The residual stress distributions in a water-quenched IN 718 compressor disc and a thin waterquenched plate of the same material were studied using FE modeling and neutron diffraction. The results showed that using a constant heat transfer coefficient already gives a good overall description of the residual stress state in the relatively thick disc after water quenching. However, a temperature-dependent heat transfer coefficient was required for a satisfying prediction of residual stresses in the relatively thin plate. Using a realistic heat transfer coefficient the influence of the different processing steps on the resulting stress state in industrial components can be predicted with good accuracy, thus allowing an optimization of subsequent treatments such as turning to final shape.

\section{References}

[1] U. Cihak, H. Leitner, H. Clemens, P. Staron, W. Marketz, and J. Tockner, Berg- und Hüttenmännische Monatshefte (BHM) Vol. 149 Heft 5 (2004), pp. 176-180.

[2] U. Cihak, P. Staron, W. Marketz, H. Leitner, J. Tockner, and H. Clemens, Z. Metall. Vol. 95 (7) (2004), pp. 663-667.

[3] U. Cihak, M. Stockinger, P. Staron, J. Tockner, and H. Clemens, in: Superalloys 718 2005, edited by E.A. Loria, The Minerals, Metals \& Materials Society (TMS), Warrendale, PA, USA (2005), pp. 517-526.

[4] U. Cihak, P. Staron, M. Stockinger, and H. Clemens, Adv. Eng. Mater. Vol. 8 (2006), pp. 1088-1092.

[5] U. Cihak, P. Staron, H. Clemens, J. Homeyer, M. Stockinger, and J. Tockner, Mater. Sci. Eng. A Vol. 437 (2006), pp. 75-82. 
[6] P. Staron, U. Cihak, M. Stockinger, and H. Clemens, J. Neutron Res. Vol. 15 (2007), pp. 185192.

[7] Superalloys 718, 625, 706 and Derivatives 2005, edited by E.A. Loria, TMS (The Minerals, Metals \& Materials Society), Warrendale, PA, USA (2005).

[8] W. Betteridge, in: Materials Science and Technology Vol. 7, VCH, Weinheim, New York, Basel, Cambridge (1992), p. 641.

[9] S.J. Hong, W.P. Chen, and T.W. Wang, Mat. Sci. Trans. A Vol. 32 (2001), pp. 1887-1901.

[10] W. Horvath, W. Zechner, J. Tockner, M. Berchthaler, G. Weber, and E.A. Werner, in: Superalloys 718, 625, 706 and Derivates, The Minerals, Metals \& Materials Society (TMS), Warrendale, PA, USA, (2001), pp. 223-228.

[11] G.A. Rao, M. Kumar, M. Srinivas, and D.S. Sarma: Mat. Sci. Eng. A, Vol. 355 (2003), p. 114.

[12] D.D. Krueger, in: Superalloy 718 - Metallurgy and Applications, The Minerals, Metals \& Materials Society (TMS), Warrendale, PA, USA (1989), pp. 279-296.

[13] M.T. Hutchings at al., Introduction to the Characterization of Residual Stress by Neutron Diffraction, Taylor \& Francis Group, Boca Raton, USA (2005).

[14] P. Staron, H.-U. Ruhnau, P. Mikula, and R. Kampmann, Physica B Vol. 276-278 (2000), pp. 158-159.

[15] A.J. Allen, M.T. Hutchings, C.G. Windsor, and C. Andreani, Advances in Physics Vol. 34 (1985), pp. 445-473.

[16] A.D. Kravitz, and R.A. Winholtz, Mat. Sci. Eng. A Vol. 185 (1994), pp. 123-130.

[17] K.C. Mills, Recommended values of thermophysical properties for selected commercial alloys, National Physical Laboratory (NPL), ASM International, Cambridge, UK (2002).

[18] G. Pottlacher et al., Thermochimica Acta Vol. 382 (2002), pp. 255-267.

[19] A.G. Hellier, S.B. Palmer, and D.G. Whitehead, J. Phys. E: Sci. Instrum. Vol. 8 (1975), pp. $352-354$.

[20] H. Chandler, Heat Treater's Guide, ASM International, Materials Park, Ohio, USA (1995), p. 88.

[21] D. Dye, K.T. Conlon, and R.C. Reed, Met. Mat. Trans. A Vol. 35 (2004), pp. 1703-1713. 